\title{
BUILDING ONLINE AND TELEPHONE PSYCHOLOGICAL FIRST AID SERVICES IN A LOW RESOURCE SETTING DURING COVID-19: THE CASE OF KOSOVO
}

\author{
Aliriza Arenliu ${ }^{1}$, Fitim Uka $^{1} \&$ Stevan Weine ${ }^{2}$ \\ ${ }^{1}$ Department of Psychology, University of Prishtina "Hasan Prishtina, Prishtina, Kosovo \\ ${ }^{2}$ Center for Global Health, University of Illinois in Chicago, Chicago, US
}

received: 19.9.2020;

revised: 26.10.2020;

accepted: 30.11 .2020

\begin{abstract}
SUMMARY
The COVID-19 pandemic and the measures brought for prevention of infections are associated with considerable psychosocial and psychological morbidity in the general population. Providing continuous mental health services during the pandemics is a challenge worldwide, especially in low-and middle-income countries (LMICs). This paper reports on the strategies and activities taken to protect public mental health during the COVID-19 pandemic in Kosovo. This included establishing online and phone psychological first aid services and developing psychoeducational videos and webinars. The paper concludes with several lessons learned during the process of establishing and maintaining these interventions, such as: initial political endorsement is crucial to gain and maintain the momentum of services; continuous training of volunteers is crucial for both addressing the needs/problems, which arise during the process of work and maintain the motivation of volunteers; promotion of the services is crucial; academic curricula training mental health professionals should include digital mental health related courses and manualization on how to establish this kind of services in midst of crisis is crucial in order to ensure quick operationalization when needed again especially in LMIC settings. The interventions developed provide opportunity for further research especially by evaluating the impact of the services and exploring how online and provision of mental health and psychoeducation services online could help to cover services gap in times of isolation, limited movement and situations similar to pandemics in settings with limited mental health services and resources. The situation with pandemics with COVID 19 is still far from ending. Future waves of infections and restriction could again spike the mental health and psychosocial and psychological strain of the general population, therefore being prepared in provisions of psychological first aid and other mental health services online is crucial.
\end{abstract}

Key words: psychological first aid services - COVID-19 - low resource setting - Kosovo

\section{INTRODUCTION}

The mental health toll of COVID-19 pandemic is being recognized as an important dimension to be addressed. Lives of billions around the globe have changed drastically by measures and its consequences taken globally to slow down the outbreak such as: social and physical isolation, protective measures, restriction of movement, quarantines, testing and tracing, loss of employment or working from home, online schooling. All these measures resulted in changes in lives of billions of individuals and could have potentially an immediate and long-term impact on physical and mental health, which require attention and intervention from policy makers and service providers (Pfefferbaum \& North 2020, Cullen et al. 2020, Usher et al. 2020; Shah et al. 2020, Moreno et al. 2020). The mental health and COVID-19 becomes even more relevant when we consider that the vaccine and medicine for this virus is still not found and the risk of the so-called second wave spread of COVID 19 is still present. COVID 19 caused states considerable degree of fear, worry and concern in populations at large (WHO 2020). From a public health perspective, the infection risks and consequences associated with infections the recent pandemics is considered to increase the level of stress and anxiety among the general population and especially to others who have had a history of mental health illness. It is predicted an upsurge of psychiatric illness linked to the emotional impact of COVID 19 and an increase in the number of persons in need of psychiatric intervention due to COVID 19 pandemic (Lazzari 2020, Marčinko et al. 2020). COVID 19 pandemic is associated with negative psychosocial consequences and mainly results in depressive symptoms, anxiety, anger and stress, sleep disorders, symptoms of posttraumatic stress disorder, social isolation, loneliness and stigmatization (Sinanović et al. 2020).

Health care infrastructure, access, available funds and governance serves to differentiate between LMIC and HIC (high income countries). This is the reason why LMIC have additional challenges in organizing mental health services during pandemics, which are elaborated by De Sousa and colleagues (2020). There are evident differences for mental health services in terms of mental health governance, financing, service delivery, human resources and information (WHO 2020) and general emergency preparedness for disasters (Kobusingye et al. 2005). Total government spending in health is lower than the average of European Union expenditures (World Bank 2014). Also, only $2 \%$ of the health budget is spent on mental health services which is again lower than the EU average of 4\% (Fanaj \& Mustafa 2018). Situation 
with COVID-19 pandemic in Kosovo was different, in June 2020 the World Health Organization put Kosovo among 11 countries in Europe with sharpest increases in new cases infected with COVID-19 (Chadwick 2020) especially as measures for movement restrictions were lifted. Similarly, as many other countries Kosovo was challenged in provision of mental health services especially services which would address the psychosocial consequences of COVID 19 pandemics.

COVID-19 pandemics disrupted usual in person services and treatment. Thus, digital mental health and offering services from distance are seen as a solution and turning point for e-mental health (Wind et al. 2020, Ćosić et al. 2020). Despite the exceptional increase in mobile telecommunications and internet access across many low-income and middle-income countries there is limited information on how these new opportunities can be reached and used to support and treat individuals living with mental disorders could function in LMIC settings. Kosovo has $93.6 \%$ internet penetration and a high percentage of GSM users with internet use (Lancaster 2020). This paper summarizes the experiences learned in using internet and phone services in provision of mental health services during pandemics in LMIC settings and strives to recommend on how these lessons learned can serve for future emergencies.

\section{PANDEMICS MARCH-JUNE 2020 IN KOSOVO}

The first cases with COVID 19 in Kosovo were tested on 13 March 2020. Along with political actions and measures all around the world, the Government of Kosovo introduced various measures aiming to reduce the number of infections and deaths from COVID 19, including restriction of movement, closing schools and universities, quarantines and other forms of measures that in general paralyzed the "normal" life. These measures and overall situation created with pandemic where expected to impact levels of stress, anxiety and depression and negative emotions in general population as found in other countries (Li et al. 2020, Nelson et al. 2020, Ranisng et al. 2020).

The situation created with Covid-19 pandemics in Kosovo combined with restrictive measures in terms of movement were associated in initial days with massive buying in supermarkets and stocking of flour and other essential food, which was considered as an effect of fear and inability to predict the future by the citizens in Kosovo. The Kosovar economy is expected to shrink by $4.5 \%$ in 2020 due to pandemics and it is expected to decrease the remittances which are important contributors to Kosovo GDP (World Bank 2020). On the other hand, the health and public health system services in Kosovo as expected were and are still predominantly focused on prevention of infection and provision of treatment for those infected. Policy level discussion and interventions ameliorating the economic and social impact of pande- mics in Kosovar context was focused predominantly on economic measures and subventions to private economy. During the initial phase of pandemics (March June 2020) mental health services in Kosovo were closed or brought to limited delivery providing services only to emergency psychiatric cases in psychiatric wards. Delivery of online and phone based mental health services was considered to be a viable solution.

\section{MENTAL HEALTH SERVICES IN KOSOVO}

Mental health services in Kosovo are provided in two levels among eight community mental health centers and psychiatric wards within general hospitals. Other mental health services are delivered by psychiatrists and psychologists which work in private practices. Except in Prishtina, which is the capital city in Kosovo, services for child and adolescent mental health are underdeveloped. In the tertiary level the mental health services are provided by the Psychiatry Clinic, Institute of Forensic psychiatry, Child and Adolescent Mental Health Center. Many countries lack disaster mental health preparedness (Roudin et al. 2017), which is valid also for Kosovar mental health services.

Some of the challenges in Kosovar context in terms of mental health services mentioned in Sousa and colleagues (2020) during COVID-19 pandemic include paucity of resources; access to proper mental health during pandemics; addressing the needs of special population such example children, adolescents; addressing various psychosocial problems such as financial problems as result of pandemics, increase in family violence, increased stress and anxiety in general population; issues with stigma on mental health in general and mental health problems; lack of telepsychiatry service; lack of emergency and preparedness plan for mental health services and general political instability.

\section{DEVELOPING ONLINE AND PHONE PSYCHOLOGICAL FIRST AID SERVICES AND PSYCHOEDUCATIONAL INFORMATION}

The Ministry of health in Kosovo and municipality of Prizren have underscored the mental health toll of pandemics and requested support of the Department of Psychology at University of Prishtina in establishment of phone and other online mental health support services providing psychological first aid during pandemics. The premise of providing help line and online mental health services during pandemics was conceptualized as an opportunity that citizens can maintain their mental health and provide an easy to access support platform for the general population to manage with COVID related changes in their lives and to adjust following easing of restrictions. Previously, emergency online of distance provision of mental health services usually were established during disasters, risk/prevention of suicide and trauma (Silva et al. 2015). 
In process of addressing the mental health needs during pandemics the staff of department of psychology has developed and delivered following services during the pandemics: (1) development of psychoeducation videos on informing and self-guided exercises to address stress, anxiety, depression and worrying thoughts; (2) development and launching of two help phone lines providing psychological first aid; (3) development and launching of chat based psychological first aid and (4) organizing and delivering webinars on topics and subjects addressing the needs of volunteers working in help and chat line, school psychologists and general population.

\section{PSYCHOEDUCATIONAL VIDEOS CONCEPTUALIZED AS SESSIONS COMBINING INFORMATION PROVISION AND SELF-GUIDED EXERCISES}

Even without the strain of pandemics in low- and middle-income countries mental disorders account for $11.1 \%$ of the burden of disease, although do not attract global health policy attention (Patel 2007). In addition to the lack of financial resources to build capacities for offering the mental health services, the citizens do not seek for the mental health services. The reasons for not seeking mental health services are related both to stigma and lack of mental health literacy or information on mental health issues (Rickwood et al. 2005). Due to situation created with pandemics, which involved high internet traffic and contextual factors, such as high stigma attached to mental health that psychoeducational videos can be appropriate method to disseminate information on mental health and reinforce usage of evidence based coping strategies to deal with eventual acute symptoms of common mental health disorder (CMD). Since the mid 1980 psychoeducation in general has evolved to an independent therapeutic program which focuses on didactical transmission of information regarding mental health especially from cognitive behavioral framework (Bäuml et al. 2006).

In order to create a structure, we have organized presentations of psychoeducation materials as separated sessions. The videos are uploaded in a page with a name www.shendetimendor.org. Four separate sessions with psychoeducation videos were developed: understanding and dealing with stress, understanding and dealing with anxiety, understanding and dealing with worrying thoughts and understanding and dealing with depressive symptoms. Each session contains one animate video providing information on CMD or related symptoms, for example anxiety and anxiety disorders. The same method is used for self-guided exercises which could be done in a home environment such as: slow breathing, muscle relaxation, grounding, and get going keep doing, mindfulness, meditation depending on which mental health problem was addressed etc. All videos range from 4 minutes to 12 minutes and length of sessions ranged from 15 to 25 minutes. During the pandemic videos had about 5000 views. Currently we are in the process of implementing a randomized clinical trial of evaluating the impact of the videos.

\section{PHONE HELPLINES FOR PSYCHOLOGICAL FIRST AID}

Telephone helplines since the 60's of last century have been used to provide information and personal advice to the general population and often are set on short notice and in times of crisis (Stark et al. 1994, James et al. 2007). It is estimated that helplines function in over 60 countries and they have been developed a strong and respected profile of providing help to people in times of crisis especially for suicide prevention (Lifeline 2013). Recently experts in crisis intervention recommend usage of Psychological First Aid (Parker et al. 2006). Although there are different models suggested in approach to work with callers basically psychological first aid focuses on meeting individuals' immediate needs which could be in crisis situations in terms of psycho-biosocial needs in practical sense by developing either action plans (Combs 2007) or referring them to appropriate services which could address their needs.

Initially, in mid-March 2020, the Prizren Municipality requested support from the department of psychology at University of Prishtina in establishment of a helpline on provision of psychological first aid during the pandemic. In the second week of April 2020 right before introducing strict movement restrictions the Ministry of Health similarly requested from the department of psychology support in establishing the help line providing psychological support. For both services around 200 volunteers graduated from psychology, graduate students and last year students applied to an open call by our department. The team was selected by seniority and those who live in the capital city as the services were provided from the building of the Ministry of Health. In total 35 volunteers provided psychological first aid through a phone 7 days a week, from 13.00 till 22.00. All applicants received a one-day training on following subjects: 1) delivering psychological first aid during COVID-19 pandemics which was based on a document developed by IFRC and which was translated in Albanian (IFRC 2020); 2) Learning from previous experiences of help lines in Kosovo and 3) Basics of phone counseling. The services were established with aim of easing the mental health strain brought by COVID-19 pandemics and measures associated with restrictions of movement and the fact that normal routines of almost all citizens were disrupted. The volunteers were guided to use the six stage framework of a helpline calls (Rosenfield 2013): 1) establishing relationship; 2) exploring the nature and purpose of call; 3) Clarification trying to understand as fully as possible the problem 4) if caller request specific information they provide, volunteers are not recommended to offer advice or opinion other than what was specified in the guidelines for psychological first 
aid IFRC (2020); 5) Ending the conversation, encouraged to use summarizing and reminding they can call again the services; 6) Documentation of the call where volunteers fill in a form. Volunteers are encouraged to use probing questions, acknowledging emotions and using empathy and open questions in all phases. Volunteers were provided with referral to reliable resources for callers on issues such as: health services, more information on COVID-19, violence against women, suicide risk, mental health services, social services etc. Also, all volunteers receive biweekly supervision from more experienced academic and clinical staff. Based on the data recorded from the April until August 2020 from 1278 recorded calls, the majority of callers are men $52 \%$, in terms of age they range from 14 to 98 years old, callers are from all around Kosovo and main concerns for call were: anxiety, depression, fear from Covid-19, financial problems, interpersonal and social problems, health issues related to Covid-19 pandemic or similar. The help line on national level was promoted twice by sending SMS to all GSM phone numbers in Kosovo. It was observed that following the promotion the number of calls on the same and next day increased 5 to 6 -fold by again getting to average 50 calls per day.

\section{CHAT COUNSELING PROVIDING PSYCHOLOGICAL FIRST AID}

Since the 1990 when the internet became public the chat counseling has seen rise in use as a form of synchronous communication between people needing mental health service and those providing it in distance. There is no agreed taxonomy of the mental health services offered online (Dowling \& Rickwood 2013). Mostly available in developed countries it is common to find psycho-educational sites, online support groups, interactive self-help programs and online services provided by psychologists (Abbott et al. 2008, Ybarra \& Eaton 2005). Use of chat counseling is documented in Low- and Middle-Income Countries (LMIC's) (Acharibasam \& Wynn 2018). Chat counseling compared to face-to-face via video or from phone counseling is characterized with "channel reduction" (Joinson 2005) as a person relies only on letters being typed. Specifically, online chatting is both faceless and voiceless with no non-verbal expressions and paralinguistic information which are considered to be important components of counseling (Fukkink \& Hermanns 2009).

We developed a secure and anonymous chat line where individuals without provision of any personal data could chat with one of our volunteers. Volunteers in the chat services as in the helpline were predominantly graduated from psychology, graduate students or last year students. Similarly, as in helpline we organized a one-day training which covered: 1) delivering psychological first aid during COVID-19 pandemics which was based on a document developed by IFRC and which was translated in Albanian (IFRC 2020); 2)
Training from experienced psychologist using chat counseling; 3) Basics of chat counseling. Furthermore, as with the helpline the academic staff conducted a quick literature review on basic principles of chat counseling and developed a manual for volunteers which included guidelines in: usage of language, emoticons, length of talk and structure of talk. The document also guided the volunteers to structure the chat talk using the six-stage framework of a helpline calls (Rosenfield 2013) adjusted to chat. Similarly, as in phone helpline volunteers are encouraged not to give advice or personal opinions related to the problems. In terms of evaluation of services, the users of services voluntarily administered a questionnaire before and after the chat. Additionally, the users of services are asked if they provide their consent so that their anonymous chat can be used for research purposes. After the chat the users are requested again voluntarily to evaluate the quality in terms of whether services are considered as helpful, whether they would use the services again and recommend to others. The services in chat are provided from $13.00 \mathrm{pm}$ till 01.00 after midnight in shifts of 10 volunteers every day. The work of chat volunteers is constantly supervised by 6 coordinators who work in shifts and receive weekly supervision from the academic staff. The chat is constantly monitored by supervisors who can intervene directly and communicate with volunteers. During April, May and June in total 808 people contacted chat services, on average the chat's with individuals lasted for 14 minutes ranging from 90 seconds to 1 hour and 12-minute, average waiting time was around 1 minute and 30 seconds.

\section{WEBINARS}

Webinars facilitate creation of digital learning environments and sessions where individuals participate with technological equipment regardless of their physical location. Organization of webinars was seen as a viable solution during pandemics for training of volunteers and professionals involved in the above-mentioned services. Since the beginning of pandemics in March till June 2020 we have organized 10 webinars with various international and national expertise focusing on following subjects: opportunities and challenges of tele-mental health, loneliness during pandemics, practical implications of research from chat and helplines counseling lines and helping others to manage acute panic and anxiety attacks. Furthermore, in collaboration with school psychologists we prioritized challenges faced by teachers, school psychologists and parents during pandemic and organized a series of separate webinars on addressing these challenges. One of the top priorities identified were challenges that parents and teachers faced with online education of children with special needs and learning disorders. As a result, we organized 5 webinars focusing on challenges and opportunities for parents and teachers with children with autism, physical 
disabilities, gifted children, Down Syndrome and career decision making during pandemics. The webinars were promoted through the social media channels of the department and about 1000 participants participated in total in all webinars.

\section{LESSONS LEARNED AND FUTURE OPPORTUNITIES}

Building online and phone psychological first aid services during pandemics of COVID-19 so far has been a great learning experience in building emergency mental health services. The following points are to be highlighted for LMIC settings which intend to set similar services:

1) Initial support from political level in central orland local level is crucial for building of services. Initial governmental support in building the services and basic financial support in building technical infrastructure of the services is very important. In developing the site with the psychoeducational materials and basic technical equipment for volunteers in the help lines were provided by the Municipality of Prizren and Ministry of Health and the rest was provided and maintained by the staff from the department of psychology.

2) Need for clarification of roles of partners involved in service provision. It is recommended that responsibilities of the partners be determined and specified in written form, if possible with memorandum of understanding. Emergency situations as with pandemics sometimes create situations where roles and responsibilities are not clearly defined. We would strongly recommend to spend some time on developing documents such as memorandums of understanding, which specify responsibilities of partners and define inclusion of new resources and partners during the process.

3) Conduct short term training and then conduct top up training during the process combined with supervision. In order to maintain the momentum of establishing services in a short time, plan short and practical training which provides hands on knowledge to volunteers to tackle with work and responsibilities. Training should be brief and followed by supervision and follow up top up training which could address the needs that are identified during supervision or coordination meetings with volunteer coordinators. Webinars were used on weekly or biweekly bases as top up training for volunteers and other mental health professionals.

4) Continuous/refresher training of volunteers in basic skills needed for psychological first aid provision. From supervision we understood the need for volunteers to be reminded of the purpose of the services that are of psychological first aid which provides mainly single intervention rather than continuous or in-depth counseling. There was a need to repeat that the aim of the services was to help distressed individuals so they feel calmer and feel supported to better cope with the challenges in life. Skills needed to be trained and reminded: empathy, attention to reactions and emotions, active listening, normalization of experiences related to pandemics, paraphrasing, offering practical experience and maintaining a positive and optimistic attitude.

5) Promotion of services is crucial. As with any other form of services promotion of service was clearly associated with higher requests for the services. On two occasions when the Ministry of Health promoted the help line by sending SMS to every GSM number in Kosovo the number of calls increased. Furthermore, promotion of services especially through social media was associated with the increase in the number of contacts with services. The services need a long-term strategy and financial support for promotion of the services.

6) Training programs in psychology need to include more training in online mental health. Currently online mental health is not taught as a course in most training programs in psychology and other mental health related professions. Due to specificities that online mental health services have programs including ours need to change curricula and include courses which can prepare future professionals on basic principles of online mental health provision.

7) Existing experience needs to be reflected in step by step activities which can be used again and quickly operationalized in case of other crises or disasters. Although there are several documents guiding establishment of crisis helplines or other forms of crisis mental health services, we consider that development of manuals which take in consideration the context and limitations of LMIC settings need to be developed. Development of such manuals could encourage duplication of existing experiences and improvement of quality of service delivery especially by taking in consideration since the start issues might be related to evaluation of the services.

8) Public mental health services need urgently to plan provision of online or telepsychiatry services. Psychological first aid helpline and chat services, occasionally dealt with cases which needed more intensive psychiatric, psycho-pharmacological and psychological support and volunteers had difficulty in referring cases to services which worked with limited capacities. Public mental health services urgently plan alternative forms of services provision using the internet or other online services especially with the warning of the second wave of pandemics.

\section{CONCLUSIONS}

Provision of mental health and psychosocial services from distance using phone and internet is a viable option in LMIC settings during pandemics. The experience in Kosovo suggests that with minimal support it is possible to use digital and remote technologies for prevention and intervention in times of crises where conventional services do not function. However, these 
services are limited to provision of psychosocial support and psychological first aid, other mental health problems requiring more intensive and treatment-based approach. Minimal government and financial support, volunteers, expertise to organize services, appear to be important ingredients in establishment of emergency mental health services during pandemics in LMIC settings. Development of psychological first aid mental health services provided by phone line, web-based psychoeducation materials and chat counseling can help substantially in identifying undetected mental health problems which usually are not addressed in times of crises. Further development and use of the digital mental health services and opportunities is needed including more rigorous evaluations in terms of quality of intervention, effectiveness and confidentiality (Balcombe \& De Leo 2020). Some initial findings from Balkan region are encouraging example provision of psychiatric services by phone was positively evaluated by services users (Haxhihamza et al. 2020). However, in order to fight the COVID-19 not only one type of intervention is needed and as suggested in recent studies all countries and nations need to join efforts on a much more creative, systemic and humanistic type of intervention (Jakovljevic et al. 2020).

The general population could significantly benefit from emergency mental health services by provision of basic information on recognizing and dealing with stress and anxiety and other disorders, orient persons for treatment and where to seek emotional support (Silva et al. 2015). Furthermore, experience in Kosovo can be seen as also an opportunity in development of web based mental health interventions when distancing is required or there is need for more equitable access to mental health services (Weine \& Bunn 2020). These services are limited in terms of how much help they can provide to more serious mental health disorders such as schizophrenia, bipolar disorders or substance abuse. Regardless of their limitations our initial experience and unstructured evaluation considers that these kinds of interventions will play a significant role during pandemics or other crisis situations as they can offer an outlet for many people who might experience acute stress, anxiety or other psychological morbidity due to crisis situations.

\section{Acknowledgements: None.}

\section{Conflict of interest: None to declare.}

\section{Contribution of individual authors:}

Aliriza Arenliu: paper conceptualization, first draft, approval of the final version.

Fitim Uka: first draft, approval of the final version.

Stevan Weine: paper conceptualization, approval of the final version

\section{References}

1. Acharibasam JW \& Wynn R: Telemental Health in Lowand Middle-Income Countries: A Systematic Review. Int $J$ Telemed Appl 2018; 2018:1-10

2. Balcombe L \& De Leo D: An Integrated Blueprint for Digital Mental Health Services amidst COVID-19. JMIR Mental Health, 2020; 7: e21718

3. Bäuml J, Froböse T, Kraemer S, Rentrop M, \& PitschelWalz G: Psychoeducation: a basic psychotherapeutic intervention for patients with schizophrenia and their families. Schizophr Bull 2006; 32:1-9

4. Chadwick L: Coronavirus: The 11 countries where WHO Europe says COVID-19 is on the rise. Retrieved from https://www.euronews.com/2020/06/26/coronavirus-the11-countries-where-who-europe-says-covid-19-is-on-therise 2020

5. Combs DC: Mental health interventions by telephone with Katrina survivors. J Health Care Poor Underserved 2007; 18: $271-276$

6. Ćosić K, Popović S, Šarlija $M$ \& Kesedžić I: Impact of human disasters and Covid-19 pandemic on mental health: Potential of digital psychiatry. Psychiatr Danub 2020; 1:25-31

7. Cullen $W$, Gulati $G \&$ Kelly BD: Mental health in the Covid-19 pandemic. QJM 2020; 113:311-312

8. De Sousa A, Mohandas E, \& Javed A: Psychological interventions during COVID-19: Challenges for low- and middle-income countries. Asian J Psychiatr 2020; 51:1-4

9. Dowling $M \&$ Rickwood D: Online counseling and therapy for mental health problems: A systematic review of individual synchronous interventions using chat. $J$ Technol Hum Serv 2013; 31:1-21

10. Fanaj $N \&$ Mustafa: State of mental health reform in light of new mental health interventions. Paper presented at 19th Congress EPA section of Epidemiology and Social Psychiatry. Retrieved from https://www.researchgate.net/ publication/324683979_STATE_OF_MENTAL_HEALTH CARE_REFORM_IN_KOSOVO_IN_LIGHT_OF_NEW_M ENTA $\bar{L} \_$HEALTH_INTERVENTIONS 2018

11. Fukkink RG \& Hermanns JM: Children's experiences with chat support and telephone support. J Child Psychol Psychiatry 2009; 50:759-766

12. Haxhihamza $K$, Arsova S, Bajraktarov S, Kalpak G, Stefanovski B, Novotni A, \& Milutinovic M: Patient Satisfaction with Use of Telemedicine in University Clinic of Psychiatry: Skopje, North Macedonia during COVID19 Pandemic. Telemedicine and e-Health 2020

13. Jakovljevic M, Jakovljevic I, Bjedov $S$ \& Mustac F: Psychiatry for Better World: COVID-19 and Blame Games People Play from Public and Global Mental Health Perspective. Psychiatr Danub 2020; 2:221-228

14. James H, Halpern J, \& Tramontin M: Psychological first aid. Disaster Mental Health: Theory and Practice. Belmont, CA: Brooks/Cole, 2007

15. Joinson AN: Internet behavior and the design of virtual methods. In C. Hine (Ed.), Virtual methods: Issues in social research on the internet. Oxford, UK: Berg, 2005

16. Kissler SM, Tedijanto C, Lipsitch M, \& Grad Y: Social distancing strategies for curbing the COVID-19 epidemic. MedRxiv 2020; 13:1-14

17. Kobusingye OC, Hyder AA, Bishai D, Hicks ER, Mock C, \& Joshipura M: Emergency medical systems in low-and 
middle-income countries: recommendations for action. Bull World Health Organ 2005; 83:626-631

18. Kosovo Agency for Statistics: Labor Force Survey in Kosovo. Retrieved from https://ask.rks-gov.net/en/kosovoagency-of-statistics/add-news/labor-force-survey-inkosovo-2019

19. Lancaster H: Kosovo-Telecoms, Mobile and BroadbandStatistics and Analyses. Retrieved from https://www.budde.com.au/Research/Kosovo-TelecomsMobile-and-Broadband-Statistics-and-Analyses? $r=512019$

20. Lazzari C, Shoka A, Nusair A \& Rabottini M: Psychiatry in Time of COVID-19 Pandemic. Psychiatr Danub 2020; 2: 229-235.

21. Li S, Wang Y, Xue J, Zhao N, \& Zhu T: The impact of COVID-19 epidemic declaration on psychological consequences: a study on active Weibo users. Int J Environ Res Public Health 2020; 17:20-32

22. Moreno C, Wykes T, Galderisi S, Nordentoft M, Crossley $N$, Jones $N$, et al.: How mental health care should change as a consequence of the COVID-19 pandemic. The Lancet Psychiatry 2020. doi:https://doi.org/10.1016/S22150366(20)30307-2

23. Nelson B, Pettitt AK, Flannery J \& Allen N: Psychological and Epidemiological Predictors of COVID-19 Concern and Health-Related Behaviors. PsyArXivPreprints. doi:10.31234/osf.io/jftze

24. Patel V: Mental health in low-and middle-income countries. Br Med Bull 2007; 81:81-96

25. Parker CL, Barnett DJ, Everly GS \& Links JM: Establishing evidence-informed core intervention competencies in psychological first aid for public health personnel. Int J Emerg Ment Health 2006; 8:83-92

26. Pfefferbaum $B$ \& North CS: Mental health and the Covid19 pandemic. $N$ Engl J Med 2020; 383:510-512

27. Qosaj FA, Froeschl G, Berisha M, Bellaqa B \& Holle R: Catastrophic expenditures and impoverishment due to outof-pocket health payments in Kosovo. Cost Eff Resour Alloc 2018; 16:1-26

28. Ransing R, Adiukwu F, Pereira-Sanchez V, Ramalho $R$, Orsolini L \& Teixeira ALS et al: Early career psychiatrists' perspectives on the mental health impact and care of the COVID-19 pandemic across the world. Asian J Psychiatr 2020

29. Rickwood D, Deane FP, Wilson CJ \& Ciarrochi J: Young people's help-seeking for mental health problems. AeJAMH 2005; 4:218-251
30. Rosenfield M: Telephone counselling: A handbook for practitioners. Macmillan International Higher Education, 2013

31. Roudini J, Khankeh HR \& Witruk E: Disaster mental health preparedness in the community: a systematic review study. Health Psychol. Open 2017; 1

32. Shah K, Bedi S, Onyeaka H, Singh R, \& Chaudhari G: The role of psychological first aid to support public mental health in the COVID-19 pandemic. Cureus 2020; 6

33. Silva JAMD, Siegmund $G$ \& Bredemeier J: Crisis interventions in online psychological counseling. Trends Psychiatry Psychother 2015; 37:171-182

34. Sinanovi O, Mufti M \& Sinanovi S: COVID-19 Pandemia: Neuropsychiatric Comorbidity and Consequences. Psychiatr Danub 2020; 2:236-244

35. Stark C, Christie P \& Marr AC: How to do it: Run an emergency helpline. BMJ 2015: 309:44-45

36. Turley B: Crisis Support The Legacy and Future of Helplines. Lifeline Foundation. Retrieved from https://www.lifeline.org.au/media/j12j5jmt/crisis-supportthe-legacy-and-future-of-helplines-2013.pdf 2013

37. Usher K, Durkin J \& Bhullar N: The COVID-19 pandemic and mental health impacts. Int J Ment Health Nurs 2013; $3: 315$

38. Weine $S$ \& Bunn M: How can the COVID-19 response advance global mental health?. Intervention 2020; 1:92

39. World Bank: Kosovo's Economy Projected to Contract by 4.5 Percent in 2020 Due to COVID-19. Retrieved from https://www.worldbank.org/en/news/pressrelease/2020/04/29/kosovo-economy-projected-tocontract-by-45-percent-in-2020-due-to-covid-19 2020

40. World Bank: Kosovo public finance review, fiscal policies for a young nation. World Bank 2014

41. World Health Organization: Mental health systems in selected low-and middle-income countries: a WHO-AIMS cross-national analysis. WHO 2009

42. World Health Organization: Coronavirus disease 2020 (COVID-19) situation report. https://www.who.int/docs/ default-source/coronaviruse/situation-reports/20200525covid-19-sitrep-126.pdf?sfursn $=887 d b d 66 \_22020$

43. World Bank: Kosovo in Figures. Retrieved from https://www.worldbank.org/en/country/kosovo 2020 a

44. Worldometers: COVID-19 coronavirus outbreak. Retrieved from https://www.worldometers.info/coronavirus/\#repro 2020

Correspondence:

Fitim Uka, PhD

Department of Psychology, University of Prishtina "Hasan Prishtina

Eqrem Cabej, nn. Prishtina, 10 000, Kosovo

E-mail: fitim.uka@uni-pr.edu 